\title{
Sources of Writing Anxiety: A Study on French Language Teaching Students
}

\author{
Veda ASLIM YETIS ${ }^{1}$ \\ ${ }^{1}$ Faculty of Education, Anadolu University, Eskisehir, Turkey \\ Correspondence: Veda ASLIM YETIS, Faculty of Education, Anadolu University, Eskisehir, Turkey. Tel: \\ 90-222-335-0580-3594. E-mail: vaslim@anadolu.edu.tr
}

Received: December 30, 2016

doi:10.5539/ies.v10n6p72

\author{
Accepted: January 31, 2017 Online Published: May 29, 2017 \\ URL: https://doi.org/10.5539/ies.v10n6p72
}

\begin{abstract}
Conducted on French Language Teaching students, this research aims to determine the causes of writing anxiety. Designed in accordance with the mixed method, a writing anxiety inventory, a language proficiency exam, a retrospective composing-process questionnaire, a writing attitude scale and semi-structured interviews were used. After identifying anxiety levels of 22 Turkish students attending French Writing Activities, course, proficiency levels, attitudes towards writing, and the composing-process have been found as possible sources of writing anxiety. Data obtained via semi-structured interviews held with students have not only confirmed these results, but also revealed new findings as to other causes of writing anxiety: classmates, time pressure on writing activities, and teacher's attitudes towards students.
\end{abstract}

Keywords: writing, writing anxiety, French as a foreign language, mixed method

\section{Introduction}

Studies on anxiety which is among individual differences and classified within affective domain have been on the rise since the end of 70s, which has yielded that this factor could inhibit language learning, influence foreign language students' success and performance, hinder language acquisition, and lower their self-esteem and self-respect levels (Horwitz, Hortwitz, \& Cope, 1986; Young, 1986; Gardner, Moorcroft, \& MacIntyre, 1987; Spolsky, 1989; MacIntyre \& Gardner, 1991; MacIntyre, 1995; Saito \& Samimy ,1996; Coulombe, 1998; Horwitz, 2001; Gregersen, 2003). Termed as 'foreign language anxiety' within language learning and observed in foreign language classes or in lessons where students have to speak in a foreign language, language anxiety is defined as "a distinct complex of self-perceptions, beliefs, feelings, and behaviors related to classroom language learning arising from the uniqueness of the language learning process" (Horwitz et al., 1986, p. 128). By the end of 80s, anxiety research took a new direction towards its influence over four basic language skills and developing new tools specific to each skill. So, new anxiety scales for speaking, writing, listening, and reading skills have been developed together with overall language anxiety scales. All these scales helped determining anxiety levels of language students across all skills, comparing students with high and low anxiety levels and those studying different foreign languages, figuring out sources of anxiety for each language skill, and aiding students in reducing their levels of anxiety.

Literature review yields that the highest and lowest levels of anxiety experienced by foreign language students belong to speaking (Negari \& Rezaabadi, 2012) and listening skills respectively (Vogely, 1998, p. 68; Elkhafaifi, 2005, p. 206; Bekleyen, 2009, p. 665; Atasheneh \& İzadi, 2012, p. 179, cited in Capan Tekin, 2015, p. 26). Interviews that Young (1992) held with experts of foreign language anxiety such as Krashen, Omaggio Hadley, Terrel, and Rardin produced consistent answers for the question, "Do language learners experience an equal amount of anxiety in all four skill areas?" (p. 163), which pointed that speaking skill was the main source of anxiety. Omaggio Hadley (ibid.) also added, "At least in writing you get to do some thinking and reflecting." Here, Hadley underlines that speaking requires immediate feedback whereas writing allows some time for learners to think, and this makes speaking more difficult and more conducive to anxiety than writing. However, writing skill also has some unique features leading to anxiety. Unlike speaking, writing does not involve gestures, mimes, and intonation, it does not address a listening audience in the immediate environment, but a reading one within a certain distance; and thus, writing entails being extra clear and precise in explaining opinions and feelings. Therefore, a writer has to have a good command of grammar knowledge and meticulously follow the 
rules of writing (such as spelling and punctuation) (Dabène, 1987, p. 43; Simard, 1992, p. 286) because as soon as the text is before the readers' eyes, there is no way back to correct any mistakes or improve any poor points as opposed to speaking, which always permits rewinding and clarifying. Thus, the text has to be meaningful, crystal clear, understandable, to the point, and straightforward. In order to achieve this, a writer has to plan the content and filter his/her opinions before starting to write, and has to be seriously careful about grammar, syntax, spelling, coherence, cohesion, page layout, style, and legibility. Designated as one of the difficult and complicated skills even in one's native language (Daly et Miller, 1975), writing in a foreign language becomes harder for learners due to target language-specific rules, and it leads to anxiety on learners. This reaction or fear against writing skill negatively influences foreign language learners' writing performance; cause them to dislike writing activities, even to perceive writing as a punishment procedure. Daly and Wilson (1983, p. 327) describe writing anxiety as "a situation and subject specific individual difference associated with a person's tendencies to approach or avoid situations perceived to potentially require writing accompanied by some amount of perceived evaluation." Anxious writers are aware that their work will be assessed by elaborateness of their ideas, their arguments, the quality of their wording, stylistic quality of their text, and "most terrifying of all, by the errors they may make in mechanics, spelling, morphology, syntax, and/or word choice" (Leki, 1999, p. 66). All these create frustration, fear, and avoidance on learners and put distance between them and writing. This frustration is generally bigger on learners who have arguments because "they are not able to find the L2 forms for expressing themselves, and they know what to say but not how to say that" (ibid., p. 67).

In this regard, the aim of this study is to determine what lies within the source of writing anxiety and what causes it to escalate by working on a group of French language students. However, the high number of research studies with this aim in the literature directed the researchers to be more specific, and the aim was set as to identify whether being unable to employ high- and low-level production processes leads to writing anxiety or not. Low-level production process refers to grammatical, syntactic, lexical, and orthographic components of a language, which build a text linguistically, and thus are highly crucial. These elements accentuate the meaning and clarity of a text. Whalen and Ménard (1995, p. 382) state that writers have to have a good command of vocabulary, grammar, and syntax knowledge in order to express their opinions in an acceptable manner. Devine, Railey and Boshoff (1993, p. 218) note that insufficient linguistic knowledge impedes writing activity. Also known as composing-process, high-level production process involves planning, writing, and editing steps that are based on adequate amount of knowledge and that help publishing structured and clear texts. As underlined by Zamel (1983, p. 180), foreign language learners who employ the composing-process "clearly understand what writing entails. They know what to anticipate, how to pace themselves, and what to focus on as they write and rewrite."

Apart from these two variables that might affect writing anxiety in a foreign language, examining if learners' attitudes towards writing also interfere with anxiety levels was also included among the aims of this study. Morissette (2000, p. 228) defines attitude as an emotional reaction an individual repeatedly displays upon facing an object, idea, or activity. This reaction may cause an individual to grow closer or apart from that object, idea, or activity (ibid.). This study aims to identify whether foreign language students' attitudes towards writing triggers and affects writing anxiety or not.

Accordingly, answers have been sought for the following five questions:

1) What are the writing anxiety levels of French language students?

2) Do their proficiency levels affect their writing anxiety?

3) Does the practice of composing-process influence writing anxiety levels?

4) Do students' attitudes against writing influence writing anxiety levels?

5) What do these students think about writing anxiety?

\section{Method}

\subsection{Research Model}

This study has been designed in accordance with mixed method, which combines use of both quantitative and qualitative methods; sequential explanatory design has been employed for this study. The quantitative part of this study has employed relational screening model since it aims to examine the relation between writing anxiety and three variables (students' proficiency levels, use of composing-process, and attitudes against writing) and to determine the existence and level of covariance. The qualitative part has been completed with semi-structured interviews. 


\subsection{Participants}

22 students studying French Language Teaching at the Education Faculty of a university in Turkey during the academic year of 2015-2016 partook in this research. They are between 20-23 years old, they are in second grade and they have been studying French as a foreign language for three years (first year: preparatory class). Students were chosen in concordance with opportunity sampling. All students taking "French Writing Activities" course were asked to participate in the study, the aim of the study was explained to them, and their consents were granted. Although the entire sample attended quantitative data collection step, two students were not interviewed since they displayed very low levels of anxiety, and finally, 20 students partook in the qualitative step. Consequently, the participants are selected with purposeful sampling which is among the non-probability sampling methods.

\subsection{Data Collection Tools}

Data were collected through four data collection tools. Following are descriptions of these tools in order of use.

\subsubsection{Writing Anxiety Inventory}

Developed by Cheng (2004), Second Language Writing Anxiety Inventory (SLWAI) was employed in order to determine anxiety levels of French language students. Consisting of 22 items, this five-point Likert type scale aims to identify levels of writing anxiety in a foreign language. Positive items of the scale are graded as "totally agree-5 points", "agree-4 points", "indecisive-3 points", "disagree-2 points", and "totally disagree-1 point". On the contrary, negative items are reversely graded: "totally agree- 1 point" and "totally disagree- 5 points". The highest and lowest scores to be obtained from the scale are 110 and 22 respectively. This grade range is divided into three parts: points between 22 and 51 refer to "low level of writing anxiety", 52-80 "medium level writing anxiety, and 81-110 "high level of writing anxiety". The scale was translated into Turkish via back translation technique in order to prevent misunderstandings. This technique entails translating a text from the target language into native language, then back to target language from native language again. So, the scale was translated into Turkish first, then back into English by a translator whose mother tongue is Turkish and expertise is English. Once there was any discrepancy between the translated version of the scale and the original one, two specialists were consulted, and necessary modifications were done. Following the translation-back translation step, the scale was administered to English language students, and the reliability of the scale was found to be .87 (reliability coefficient of the original scale was calculated to be .91 by Cheng).

\subsubsection{Language Proficiency Exam}

Language proficiency test is composed of four parts and 40 questions, and it takes 30 minutes to finish the test (CCIP, 2001, pp. 57-61). The first 10 questions regard vocabulary and sentence meaning, following 5 questions are about finding synonyms for words underlined in texts, next 20 questions are about grammar, and the final 5 questions are about determining the grammar mistakes in texts. Each correct answer is for 1 point and wrong answer is for zero point. Accordingly, the highest and lowest scores that one can score on this test are 40 and 0 respectively. Students were divided into three based on their scores as follows: 0-15 points, low level of French proficiency; 16-29 points, medium-level of French proficiency; and 30-40 points, high level of French proficiency.

\subsubsection{Retrospective Composing-Process Questionnaire}

The purpose of retrospective composing-process questionnaire is to check if students employed composing-process or not during writing their texts. Therefore, students were asked to write a 40-line composition about «It is not necessary to know a foreign language other than English» prior to the application of the questionnaire (in one hour). Here the aim was not to grade students' writing performance, but to help them become more objective while filling out the questionnaire. Thus, students were administered the questionnaire right after they finished their compositions, and they were asked to respond either as 'Yes' or 'No' to statements 7 of which are about planning step, 10 of which regard writing step, and 12 of which are about editing step. According to Sasaki and Hirose's study (1994, cited in Kamimura, 2000), positive responses to the questions in this questionnaire developed by Kamimura (2000) are worth points between 1-to-3 and negative responses are worth 0 point (Appendix). The highest and lowest points to be scored on this questionnaire are 59 and 0 respectively. Students scoring between 40 and 59 were grouped as those using composing-process. Developed in English originally, this questionnaire was also back-translated and administered to the research sample in Turkish. Since the measurement tool was a questionnaire, there was no need for reliability-validity analysis: often experts are consulted — an analytic approach — when using questionnaires and validity-reliability calculations are carried out with scales. 


\subsubsection{Writing Attitude Scale}

Participants were also administered an attitude scale about writing in a foreign language. Developed in Turkish by Inal (2006), this 5-point Likert type scale consists of 40 items, 23 of which are positive and 17 of which are negative statements. Grading for the positive statements in the scale is as follows: "totally agree" 5 points; "agree" 4 points; "indecisive" 3 points; "disagree" 2 points; and "totally disagree" 1 point. On the contrary, negative statements have a reverse grading system such as "totally agree" is for 1 point and "totally disagree" is for 5 points. Reliability coefficient of the scale was calculated to be .9440 , and the highest and lowest scores one can get on this scale are 200 and 40 respectively (Inal, 2006, p. 171). Again this score range was also divided into three in order to form three groups for students: scores between 40 and 93 "negative attitude against writing"; 94-146 "neutral attitude against writing"; and 147-200 "positive attitude towards writing".

\subsubsection{Semi-Structured Interviews}

Data obtained through semi-structured interviews served clarifying writing anxiety experienced by the participants and supporting, verifying, and checking the validity of the findings concluded via quantitative data. All interviews lasted 20-25 minutes, were conducted in Turkish, and were audiotaped.

\section{Data Analysis and Limitations}

Quantitative data were analyzed by SPSS version 19 program: Kruskal-Wallis test, Mann Whitney U test and Spearman correlation test were used. The interviews were recorded; transcribed and analyzed using content analysis which involved coding, sifting and categorizing.

This study is limited by the small sample size (22 learners), the quantitative data obtained from Second Language Writing Anxiety Inventory, language proficiency test, retrospective composing-process questionnaire and writing attitude scale. It is also limited by the qualitative data obtained from semi-structured interviews.

\section{Results}

22 participants were grouped under 3 categories based on the scores they got on writing anxiety inventory to be able to answer the first research question (What are the writing anxiety levels of French language students within the sample?): low-level, medium-level, and high-level.

Table 1. Writing anxiety levels of French language students

\begin{tabular}{cccccc}
\hline \multicolumn{2}{c}{ High-Level Writing Anxiety } & \multicolumn{2}{c}{ Medium-Level Writing Anxiety } & \multicolumn{2}{c}{ Low-Level Writing Anxiety } \\
\hline Students & Scores & Students & Scores & Students & Scores \\
N01 & 89 & N05 & N07 & 77 & N15 \\
N02 & 96 & N09 & 77 & \\
N03 & 95 & N11 & 77 & \\
N04 & 93 & N12 & 68 & \\
N06 & 84 & N16 & 77 & \\
N08 & 85 & & 58 & \\
N10 & 95 & & & \\
N13 & 106 & & & \\
N17 & 89 & & & \\
N18 & 106 & & & \\
N19 & 98 & & & \\
N20 & 91 & & & \\
N21 & 91 & & & \\
N22 & 102 & & & \\
\hline
\end{tabular}

Student \#: 22

low-level anxiety: 22-51

Mean: 83.32

medium-level anxiety: 52-80

Standard deviation: 18.77

high-level anxiety: 81-110

According to Table 1, all students experience a certain amount of anxiety when writing in French, except for two students with low-levels of anxiety (N14 and N15): 14 participants have high-levels of anxiety whereas 6 of them go through medium-levels of anxiety. Students with the highest levels of anxiety are N13 and N18 who both scored 106. Considering that the highest possible score one can get on this inventory is 110 , one can 
conclude that these students' levels are seriously high. Similarly, N22 who scored 102 should also be noted as experiencing a considerable amount of anxiety while writing in French. On the other hand, student N15 should be reported as the one with the lowest level of writing anxiety since s/he scored 29 and the lowest possible score is 22 . Another point worth mentioning is the fact that 6 students grouped within medium-level of writing anxiety scored 77, which is really close to high-level anxiety threshold, 81 .

Kruskal-Wallis test was employed in order to see whether levels of writing anxiety experienced by the participants varied significantly across language proficiency levels (second research question). Being a non-parametric test and alternative for Anova test, Kruskal-Wallis test is used when distribution variance is not homogeneous, participants are fewer than 35, and at least three samples are compared. Because 22 participants were grouped under three categories (Table 2) in our study, it would not be wrong to state that all criteria of Kruskal-Wallis were met.

Table 2. Language proficiency (LP) levels of French language students

\begin{tabular}{cccccc}
\hline \multicolumn{2}{c}{ High-Level LP } & \multicolumn{2}{c}{ Medium-Level LP } & \multicolumn{2}{c}{ Low-Level LP } \\
\hline Students & Proficiency Scores & Students & Proficiency Scores & Students & Proficiency Scores \\
N14 & 30 & N03 & 19 & N01 & 15 \\
N15 & N05 & 19 & N02 & 13 \\
& N06 & 20 & N04 & 14 \\
& N07 & 22 & N17 & 15 \\
& N08 & 18 & N18 & 15 \\
& N09 & 17 & N19 & 14 \\
& N10 & 23 & N20 & 13 \\
& N11 & 18 & N22 & 14 \\
\end{tabular}

As can be seen in Table 2, only 2 students have high-levels of language proficiency (N14 and N15). 11 participants with scores between 16 and 29 were labeled as having medium-level proficiency whereas 9 students with scores lower than 15 were grouped under low-level language proficiency.

Table 3. Kruskal-Wallis test results of participants' total writing anxiety scores across French language proficiency levels

\begin{tabular}{lcccccc}
\hline Proficiency Levels & $\mathbf{n}$ & Mean Rank & $\mathbf{d f}$ & $\mathbf{X}^{\mathbf{2}}$ & $\mathbf{p}$ & Significant Difference \\
\hline Low & 9 & 15.94 & 2 & 9.900 & .007 & Low-Medium, Low-High, \\
Medium & 11 & 9.68 & & & & Medium-High \\
High & 2 & 1.50 & & & & \\
\hline
\end{tabular}

Kruskal-Wallis test results in Table 3 indicate that writing anxiety levels of participants vary significantly across their language proficiency levels $\left(\mathrm{X}^{2}=9.900, \mathrm{p}<0.05\right)$. Mean ranks of groups point that writing anxiety increases as proficiency levels decrease. The results of Mann Whitney $U$ test conducted in order to determine the source of the difference observed in Kruskal-Wallis test results yield that this difference holds true across all proficiency levels and that the difference is statistically meaningful in favor of those with higher proficiency levels. In short, those with low-level proficiency experience higher levels of writing anxiety compared to those with medium and high-level language proficiency. Likewise, high-level language proficiency participants go through lower levels of writing anxiety as opposed to those with medium-level language proficiency.

In addition, mean scores of writing anxiety depicted in Table 4 clearly shows that anxiety levels go up as proficiency levels go down. 
Table 4. Writing anxiety means across proficiency levels

\begin{tabular}{lc}
\hline Proficiency levels & Writing anxiety means \\
\hline High & 39.5 \\
Medium & 81.73 \\
Low & 95 \\
\hline
\end{tabular}

Subsequently, Spearman correlation test was employed in order to check whether use of composing-process had any influence over writing anxiety or not (third research question). This test determines the direction and strength of the relation between two variables, if there is any. Being the non-parametric equivalent of Pearson correlation test, Spearman correlation test is administered when the relevant variables do not have a normal distribution and when research sample is smaller than 30. Correlation coefficient ranges between -1 and +1 : coefficients between 0 and +1 mean that there is a positive relation between two variables, which means that variables either increase or decrease simultaneously; others between -1 and 0 point to a negative relation, which means that one of the variables increases (decreases) as the other one decreases (increases). Tabel 5 depicts the results of Spearman correlation analysis.

Table 5. The results of correlation analysis between writing anxiety experienced by French language students and use of composing-process

\begin{tabular}{ccc}
\hline & \multicolumn{2}{c}{$\mathrm{r}$} \\
\cline { 3 - 3 } Writing anxiety-Composing process & Spearman Correlation & $-.602^{*}$ \\
& Sig. (2 tailed) & .003 \\
& $\mathrm{~N}$ & 22 \\
\hline
\end{tabular}

$* \mathrm{p}<.01$.

Table 5 displays that there is a medium level (-.602) $[-0.75<\mathrm{r}<-0.6]$, negative, and highly significant $(\mathrm{P}=.003<.01)$ relation between writing anxiety and use of composing-process. Accordingly, the relation between these two variables is inversely proportional i.e. writing anxiety increased when students did not use composing process and vice versa. Table 6 depicts writing anxiety total scores and composing-process questionnaire total scores for each student in order to further clarify these results.

Table 6. Total scores obtained from writing anxiety inventory and composing-process questionnaire

\begin{tabular}{ccc}
\hline Students & Writing anxiety scores & Composing-process scores \\
\hline N01 & 89 & 16 \\
N02 & 96 & 13 \\
N03 & 95 & 17 \\
N04 & 93 & 12 \\
N05 & 77 & 26 \\
N06 & 84 & 19 \\
N07 & 77 & 9 \\
N08 & 85 & 38 \\
N09 & 77 & 36 \\
N10 & 95 & 30 \\
N11 & 68 & 31 \\
N12 & 77 & 32 \\
N13 & 106 & 27 \\
N14 & 50 & 45 \\
N15 & 29 & 40 \\
N16 & 58 & 21 \\
N17 & 89 & 22 \\
N18 & 106 & 6 \\
N19 & 98 & 9 \\
N20 & 91 & 8 \\
\hline
\end{tabular}




\begin{tabular}{lcc}
\hline $\mathrm{N} 21$ & 91 & 8 \\
$\mathrm{~N} 22$ & 102 & 12 \\
\hline
\end{tabular}

Table 6 shows that students with high levels of writing anxiety scored dramatically low on composing-process questionnaire. For instance, student N18 scored 106 on the anxiety scale and 6 on the composing-process questionnaire, which clearly indicates a serious level of writing anxiety and almost no use of composing-process. On the contrary, students N14 and N15 who got 50 and 29 points respectively on the anxiety scale scored considerably high on composing-process questionnaire, 45 and 40 respectively. However, composing-process scores of two students ( $\mathrm{N} 08=38$ points, $\mathrm{N} 09=36$ points) whose anxiety levels are within medium range display that these students made use of the composing process. One can assume that these students did not end up feeling high levels of anxiety since maybe they at least tried to use the composing-process.

Spearman correlation test was employed one more time in order to answer the forth research question (Do students' attitudes against writing influence writing anxiety levels?). Results of relevant analysis are presented in Table 7.

Table 7. Results of correlation analysis between French language students' writing anxiety levels and their attitudes against writing

\begin{tabular}{lll}
\hline & & $\mathrm{r}$ \\
\cline { 2 - 3 } Writing anxiety - Attitude & Spearman Correlation & $-.503^{*}$ \\
& Sig. (2 tailed) & .017 \\
& $\mathrm{~N}$ & 22 \\
\hline
\end{tabular}

$* \mathrm{p}<.05$.

According to Table 7, there is a negative, low-level (-.503) [-0.7 $<\mathrm{r}<-0.5]$, and highly significant $(\mathrm{P}=.017<.05)$ correlation between writing anxiety levels and attitudes against writing. So, the relation between two variables is inversely proportional i.e. writing anxiety increases if accompanied by negative attitude and decreases if students bear positive attitudes against writing. For further clarification, Table 8 depicts total scores of writing anxiety inventory and writing attitude scale for each student.

Table 8. Total scores obtained from writing anxiety inventory and writing attitude scale

\begin{tabular}{ccc}
\hline Students & Writing anxiety scores & Writing attitude scores \\
\hline N01 & 89 & 121 \\
N02 & 96 & 92 \\
N03 & 95 & 155 \\
N04 & 93 & 133 \\
N05 & 77 & 128 \\
N06 & 84 & 137 \\
N07 & 77 & 125 \\
N08 & 85 & 101 \\
N09 & 77 & 122 \\
N10 & 95 & 143 \\
N11 & 68 & 155 \\
N12 & 77 & 125 \\
N13 & 106 & 128 \\
N14 & 50 & 153 \\
N15 & 29 & 149 \\
N16 & 58 & 131 \\
N17 & 89 & 122 \\
N18 & 106 & 82 \\
N19 & 98 & 99 \\
N20 & 91 & 56 \\
N21 & 91 & 93 \\
N22 & 102 & 66 \\
\hline
\end{tabular}


As can be filtered from Table 8, N02, N18, N20, N21, and N22 are students with negative attitudes against writing and high levels of writing anxiety. Similarly, two students with low levels of anxiety hold positive attitudes against writing. These results support those obtained from correlation analysis. However, anxiety and attitude scores of N01, N04, N06, N08, N10, N13, N17, and N19 show that these students go through medium level of writing anxiety although they bear positive attitudes against writing. Interestingly, N03 suffers from high level of anxiety even though $\mathrm{s}$ /he holds positive attitudes against writing, which may be noted as one of the reasons why the level of correlation between these two variables is low.

Finally, collected through semi-structured interviews in order to determine what French language students think about writing anxiety, qualitative data was studied via content analysis. Students N14 and N15 were excluded from the interview sessions since they had real low levels of writing anxiety, and interviews were completed with 20 students. Content analysis is a research method that entails spotting components repeatedly existing in a written or oral discourse, converting them into numbers, categorizing them across themes, sub-themes, and titles based on their frequency, and making inferences (Wanlin, 2007, p. 249).

So, 20 students' opinions stated during the interviews were listened and coded, and issues verbalized by most of the students were grouped under two categories; 1- Anxiety felt during writing in French; 2- Reasons to anxiety felt during writing in French (this theme was further divided into four sub-themes based on students' opinions).

All 20 students interviewed stated that they experienced some level of anxiety when it comes to writing in French. Following are some quotes concerning the first theme:

"French writing class creates anxiety on me. I don't know why, but it happens. Yet, I have to admit that I am more anxious in speaking class. I would always choose writing class over speaking if I'm ever given the chance." (N01)

"I can't write. When I see others writing during the class, I grow anxious. Therefore, I sometimes choose to put my head on the desk and rest. I try not to think about the class." (N18)

"Reading is fine, but not writing. People generally say, 'The more you read, the better you will write'. I don't think so. I read lots of books and stories in French, but when it comes to writing, I don't know what to do. Writing is not easy. Still, I'm better this year. It was worse last year; I even didn't want to come to school. I wouldn't do my homework assignments. I guess I'm less anxious in writing classes this year thanks to the teacher: I still have some concerns but I'm not afraid at least" (N13)

"I'm terribly anxious in classes, seriously. My heart starts beating crazily when I have to write. I even start to sweat. Even now, only thinking about it makes me anxious. I was more comfortable and relax last year because there were 40 students in the class. So, it was easy to avoid the teacher. It wasn't possible for the teacher to track everybody. But, we are 22 people in class this year. I'm sure the teacher will ask me to do something till the end of the class." (N02)

"I have a good command of grammar and vocabulary; thus, I think I must be comfortable in writing classes...but I'm not. As soon as the teacher tells us the instruction, I can't get my mind and opinions together, I can't form sentences... and I feel that my heart goes insane because I know the teacher will start walking among the desks to see how well we're doing. I always try to put down one or two sentences on my paper before s/he arrives; I don't want him/her to see a blank page." (N10)

"I'm afraid to write in class. Writing turns out to be a nightmare for me. Actually, I keep a diary in French. I like writing in French. Last year, I showed several pages from my diary to my teacher, and s/he said my work was pretty good. Yet, it is different in the class. There are rules and instructions, time pressure. I prefer free writing without any instructions." (N12)

"Writing in French puts pressure on me. You know what, I like writing, I write much in Turkish, but it is different in French... I guess I feel anxious when it comes to French because I can't write as well as I do in Turkish. I'm really slow when I write in French; I spend a lot of time writing very short sentences." (N05)

"I'm a stressed and hasty person, and when it comes to writing I'm overwhelmed by anxiety. Actually, I like writing classes... Courses do not reduce my motivation, either. But, writing is not like speaking. When I have to write, I have to use all my linguistic and world knowledge... I have to express myself clearly. Readers have to be able to understand my text. In speaking, we can understand each other in one way or the other. It becomes more difficult in writing." (N03)

"For me, this class (French writing) is a total nightmare. I'm not motivated for this class at all. Teachers can't motivate me either. I stopped writing, and I got worse. I don't even come to classes. I don't do the assignments 
[...] I don't know how to be successful in the exams." (N22)

"Indeed, I'm fond of writing classes. I like seeing how structures we learned in grammar classes are used in texts. But, I get nervous when I have to write. I feel like my palms sweat. Sometimes, I feel I blush. Even worse, I start stuttering when I'm asked to read what I wrote out loud. I guess I'm not that much creative, I can't write." (N06)

"I feel anxious before I start writing. But, once I start, everything gets back to normal. The most difficult part is to start for me." (N11)

"I'm good at French grammar, and this gives me confidence. If the topic I'm supposed to write is something I'm knowledgeable about, everything is fine for me. If I don't have much information about the topic, I start worrying. Yet, I somehow manage to find my way." (N08)

Table 9 displays the sub-themes within the second theme and the numbers of students mentioning these sub-themes. The second theme aims to understand the reasons of writing anxiety based on students' opinions.

Table 9. Distribution of students across sub-themes

\begin{tabular}{ll}
\hline Reasons of writing anxiety & $\mathrm{n}^{* / 20}$ \\
\hline a- Other students/Classmates' attitudes & 18 \\
b- Limited linguistic knowledge and writing skill problems & 15 \\
c- Limited time & 12 \\
d- Teacher's attitude & 9 \\
\hline
\end{tabular}

* Numbers of students mentioning sub-themes.

Almost all anxious students (18 out of 20) point their classmates as one of the sources for their anxiety. Following are several quotes by these 18 students:

"When our teacher asks us to go to the board and write on it, I pray that s/he won't choose me. My anxiety disappears only when I understand that I won't go to the board. As soon as I stand in front of the board, I start trembling. I prefer sitting in my desk trying to write on my own or copying what others write onto the board in my notebook. I feel like everybody is watching me when I stand in front of the board, and this makes me drastically anxious." (N21)

"Our teacher gets mad and rebukes when we don't volunteer to go and write our sentences onto the board. Maybe s/he is not wrong, but writing when everybody is looking is not easy for me. I don't feel comfortable and relax even when I do the assignments at home... I know there may be lots of mistakes in my assignments...So, the sentences I write in a limited time in the classroom will be worse in terms of mistakes... My teacher is tolerant, but my friends [classmates]... I don't want them to make fun of me." (N05)

"[...] when it comes to writing in class, everything changes. More precisely, when the teacher announces that some of us will write their sentences onto the board, everything changes dramatically. I start feeling anxious, even my heart beats faster than normal. These feelings prevent me from writing: I can't write anything because I constantly think that I'll go to the board. I don't want to stand in front of everybody and write." (N12)

"I'm a shy person, and I get nervous quickly... I don't want to go to the board. [...] I worry a lot... I don't want others to see that I can't do something. Actually, I'm not afraid of making mistakes: the teacher sees my mistakes, and corrects them, which is really good. My problem is my classmates. I do not want them to see my mistakes." (N03)

"What worries me indeed is to go to the board and write onto it... You know what, we all started to learn French together... We've been classmates for 3 years, and some of my classmates are way better than I am... I couldn't improve my French as much as they have." (N01)

"It's no problem to go to the board and write my text onto it. What bothers me is that the teacher asks my classmates to find my mistakes: I prefer him to see my mistakes, not my classmates." (N18)

"I become nervous and anxious when I see others write. They look like they constantly write. I feel pain in my stomach as I see them in action. Sometimes, I don't even start writing... I just wait.” (N18)

Besides, 15 participants stated their limited knowledge about linguistic features, especially vocabulary, as a major reason for their writing anxiety. Some of them noted that they couldn't complete what writing requires apart from linguistic knowledge: 
"I experience anxiety during writing especially because my vocabulary inventory is limited. I don't have any grammar issues. I score really high in grammar. Yet, my vocab knowledge is poor... We need words to be able to write." (N11)

"I'm not afraid of not knowing. It doesn't worry me. But, I know that writing will be easier and better if I knew more about words. I wonder how others [classmates] learn this many words." [N07]

"I can't put what I learn in grammar classes into practice. Plus, my vocabulary is really limited. Last year, we had a vocabulary course; we had to memorize loads of words... I'm bad at memorization. In addition, I can't gather my ideas, I can't organize them. I don't know how to do that." (N02)

"I feel anxious because I know that I won't be able to write although I have many opinions: it takes a good command of vocabulary and grammar to be able to share opinions." (N09)

"When I edit my writing, I pay special attention to correct my grammar and punctuation mistakes; still I can't get good grades. My teacher tells me that I neglect the requirements of writing and that writing does not only mean to produce grammatical sentences. What are the requirements of writing anyway? Not knowing this makes me anxious... There is always something missing." (N06)

"The other day, our teacher said that we should also take socio-cultural components into account while writing. This made me even more anxious. I do not have enough vocabulary...I don't like writing either... Plus, I have to be careful about many other things. All of these discourage me... I didn't know writing was this much difficult. I think I will fail, and I will have to take this class again next year. I don't think I'll take the final exam." (N20)

"I need to improve my grammar. I can't write properly with what I know about French right now. I feel nervous, but to be honest, I'm not that much stressed out. I know the rules of writing, how to plan writing, and that I need to be careful about cohesion, but I can't apply them... As I said, I know what to do but I don't have enough grammar and vocabulary knowledge to actually do them." (N16)

As for 12 participants, time limitation is another reason of writing anxiety. Students mostly talk about times when they do their homework assignments at home as they mention time pressure:

"As soon as the teacher gives the instruction in the class, my palms start sweating. Sometimes, I feel that I blush up to my ears. I perform better at home. I have as much time as I need, and there is the Internet. I can check many things online. Even, sometimes I write the sentences that I want to use in my writing onto the search engine, and I find similar sentences. I correct my own sentences in accordance with those I find online. I feel lots of stress in class, the time is limited; there is always time limitation in class." (N04)

"For me, being at home and in class is not the same thing. I have no problems at home. I regularly do my homework assignments. Somehow I find my way at home since time is not a limitation. Plus, I have plenty of books that I can refer. Especially, there is the Internet, which I can use when I need. Thus, words are not a problem anymore. Moreover, I can read and edit my writing as many times as I want." (N17)

"I don't know how to start a text. When we were supposed to write only sentences, I had no problem. But, writing a text is whole another thing. It is a real problem for me, I stress out in class. I know that I have to think, produce opinions, and plan my writing before I start, but...Doing all these in class is time consuming...plus, time is also limited ..." (N19)

"I'm really calm at home. I write whenever I want, whenever I feel ready, there is no time limitation. Sometimes I start writing, then I stop, and two hours later I continue writing. Most importantly, if I have little or no information about the topic, I have enough time to search about it at home. I usually find some ideas to write down about the topic. Doing assignments is quite different: I have plenty of time to check and correct my sentences." (N10)

"Time limit in class puts me under pressure. Sure, the teacher is right, s/he has to teach many things to us in a limited time. Yet, we're going so fast sometimes... If I understand that I won't finish on time, then I quit. I don't like it either, but this happens. Limited time prevents me from thinking." (N02)

"For instance, I never feel anxious at home. Often I tell myself, "You should feel the same in class." However, as soon as the instruction is given and the clock starts spinning, everything ends for me. Tremor starts. You can't imagine the exams... I feel worse in exams." (N12)

"I don't feel nervous when I do my homework at home. Seriously, no anxiety. I can take my time, I have my dictionary with me, I look up anything as I wish." (N01)

Furthermore, 9 participants associate being anxious during writing with their teacher's attitudes. 
"Lessons should be fun. There should be group works. Teacher shouldn't be so strict. What cause anxiety on us are authoritarian manners." (N05)

"Teachers' attitudes matter. Authoritarian teachers lead to anxiety on students. Instead, they should motivate us. Sure, I sometimes understand the teacher." (N04)

"Teacher's attitudes against us matter a lot. They should be sources of motivation not anxiety." (N21)

"I forget my anxiety when the lesson is fun and the teacher motivates us. Time flies by." (N09)

"Generally, all teachers should motivate their students. This is their job. I'm a very anxious person, and I get nervous too quickly. Yet, my anxiety vanishes immediately when the teacher motivates me. I totally forget about my anxiety if the teacher is motivating. To tell you the truth, I experience serious levels of anxiety during writing class." (N22)

\section{Conclusion and Suggestions}

Writing anxiety is a student's reaction characterized by emotional symptoms such as sadness, fear, and anger or physical symptoms such as blushing, sweating, and stomachache when writing is compulsory (Daly \& Wilson, 1983, p. 327). This reaction prevents students from fulfilling the requirements of writing, negatively influences the quality of writing, impedes the acquisition of sophisticated writing skill, reduces motivation and self-respect, inhibits thinking process, and causes students avoid writing (Petzel \& Wenzel, 1993).

This research aimed to determine the reasons of writing anxiety via working on French language students and employing several measurement tools.

Findings show that only 2 participants are anxiety-free whereas 14 experience high-levels and 6 go through medium-levels of writing anxiety. Analysis carried out to see if language proficiency was a reason for writing anxiety has indicated that there is a significant relation between these two variables, that language proficiency influences writing anxiety, and that anxiety decreases as proficiency increases. The fact that those two participants with very low-levels of anxiety have high language proficiency supports this finding. 20 participants experiencing medium-to-high levels of anxiety have been noted to have low-levels of language proficiency. Literature review completed by Lefrançois $(2001$, p. 232) underlies that linguistic features profoundly disturb foreign language students.

As for composing-process questionnaire, failure to employ this process (planning-writing-editing) leads to increase in anxiety levels; an inversely proportional relation has been found between anxiety and composing process: anxiety increases as composing*process is not employed. A similar result was noted in Bloom and Alrich's study (cited in Cheng, 1998, pp. 56-57). In their research, students' anxiety levels increased as participants were not able to plan or were incapable of planning their writing, could not carry out editing tasks, and could not express their opinions in a consistent framework.

Lastly, another finding distilled from quantitative data is that writing anxiety escalates with negative attitudes against writing born by students.

Qualitative data obtained from semi-structured interviews held with 20 students experiencing medium-to-high levels of anxiety are supportive of findings concluded with quantitative data set. Analysis of interviews has revealed that students mostly stated their limited knowledge and inability to complete the requirements of writing as the sources of their anxiety. A majority of participants underlined limited vocabulary inventory as the main source: according to them, knowing many words means being less anxious. Another finding concluded from qualitative data set is that students mostly think that they have enough command of grammar to write. However, none of the participants mentioned spelling or punctuation, which are among important components of writing. In fact, being easily notable, spelling mistakes can degrade the quality of a text, or even can cause the message in the text to be misunderstood. This may be interpreted as/that the participants are not aware of the significance of spelling or not conscious enough to know that it should not be neglected (or, they do not have any problems about spelling/pronunciation!).

Some of the participants noted that they had negative attitudes against writing by stating that they were not motivated for writing and they didn't like it much. This is another further indicator that qualitative and quantitative findings of this research match. Moreover, participants pointed their classmates as the primary reason for their anxiety, which was followed by time pressure and teachers' attitudes.

Of all 20 interviewees, 18 reported that writing in front of others (classmates) caused anxiety and nervousness, that they did not want their classmates to tease them, and that they did not want others to know the mistakes they made. Some of these shy students manifest physical symptoms such as increased heart rate and stomachache. It 
is understood that they constantly compared themselves with their classmates, focused on what others thought about them, and never considered themselves as successful and skillful as their classmates. Only the teacher's judgments and feedback seem natural and meaningful for these students whose self-respect levels are low, which is consistent with Krashen's findings (1990, cited in Young, 1991, p. 427) concluding that high-levels of self-respect is associated with low levels of anxiety. Likewise, Price (1991, cited in Wang, 2005, p. 29) states that "anxious learners believed that their language skills were weaker than those of the other students in the class, and that their classmates would look down upon them."

Time pressure was stated as a crucial reason for writing anxiety by 12 participants in this research, and they explained this by referring the homework assignments they did outside the school. They expressed that they were never anxious doing their assignments although the tasks were similar to those they had to do in class. They noted that they spared more time to writing, they were able to use different resources (dictionaries, course books...), and that they appealed to the Internet whenever they wanted, all of which helped them write better and feel less anxious, if any.

Finally, 9 participants said that strict, authoritative, and unmotivating teachers were also another reason for writing anxiety. On the other hand, some students reported that their teachers were not that much rigid while giving feedback or correcting their mistakes, rather they were understanding and tolerant. Furthermore, they stated that they wanted feedback from their teachers not classmates. Therefore, what participants pictured during the interviews as strict and inconsiderate teachers was interpreted as those who do not care much about teacher-student interaction, who ignore creating a positive classroom setting and humor, and who sees intimidation as a necessary component of classroom environment. As also underpinned by Brandl (1987, cited in Young, 1991, p. 428), many teachers consider "a little bit of intimidation a necessary and supportive motivator for promoting students' performance". In fact, "the facilitation of significant learning is largely a function of certain attitudinal qualities that exist in the interpersonal relationship between the teacher and the student" (Weber, 1986, p. 315 akt. Lusignan, 2001, p. 21).

Research findings indicate that the role of teacher is crucial in reducing writing anxiety. It is obvious that teachers' roles and duties are of great importance in terms of both their attitudes and teaching the rules of writing to students, which diminishes levels of anxiety. First of all, teachers should inform foreign language students about the following points:

- Linguistic elements are significant but not the only necessary component of a successful writing; they are just "an additive factor increasing the quality of the text". (Cumming, 1989, p. 81);

- Writing entails use of composing-process: planning, reflecting the plan in writing, reviewing the draft, and correcting the mistakes;

- Developing negative attitudes against writing impedes acquisition of composition skills: students should be more positive about the course, and should talk about the factors that may influence their attitudes.

Besides,

- Considering that his/her attitudes impact students' success, teachers should have more lively classes, be more active during the lesson, provoke desire to learn in their students, have a sense of humor, and display positive attitudes. Only in such settings do students feel free to talk abbot their problems related with the course;

- Promoting interaction, pair and group works should be integrated in lessons more often so that students can know each other better, see they are not worse than others, and witness that even the best and talented students can make mistakes. For instance, creative writing activities prepare students for writing emotionally and offer opportunities for group work;

- Teachers should co-operate with their students about composing-process. Students' written works should be handled in accordance with planning, writing, and editing steps;

- Teachers should not miss the chance to teach linguistic features such as grammar and vocabulary; they should incorporate them into writing class whenever possible and necessary. For example, word-hunt games can be played through brain-storming, which enhances fun and participation;

- Students should be given enough time to plan how to start writing and what to write. Teachers should take this into account while planning class time;

- Teachers should guide students, praise them on the spot, and comfort them by telling that they should not be afraid of making mistakes. 


\section{References}

Çapan Tekin, S. (2015). Réduire/Vaincre l'anxiété langagière en production orale avec les jeux de rôles: une expérience avec des étudiants de FLE de l'Université Anadolu (Unpublished master's thesis). University Anadolu.

CCIP/Chambre de Commerce et d'Industrie de Paris. (2001). Test d'évaluation du français-Livre de l'élève. France: Hachette FLE

Cheng, Y-S. (1998). Examination of two anxiety constructs: Second language class anxiety and second language writing anxiety (Unpublished $\mathrm{PhD}$ thesis). University of Texas.

Cheng, Y-S. (2004). A measure of second language writing anxiety: Scale development and preliminary validation. Journal of Second Language Writing, 13, 313-335. https://doi.org/10.1016/j.jslw.2004.07.001

Coulombe, D. (1998). Anxiété et croyances langagières chez des apprenants d'une langue seconde au niveau universitaire. Retrieved January 12, 2016, from http://files.eric.ed.gov/fulltext/ED424764.pdf\#page=43

Cumming, A. (1989). Writing expertise and second language proficiency. Language Learning, 39, 81-141. https://doi.org/10.1111/j.1467-1770.1989.tb00592.x

Dabène, M. (1987). L'Adulte et l'Ecriture - Contributions à une Didactique de l'Ecrit en Langue Maternelle. Bruxelles: De Boeck Université.

Daly, J. A., \& Wilson, D. A. (1983). Writing apprehension, self-esteem, and personality. Research in the Teaching of English, 17(4), 327-339.

Daly, J. A., \& Miller, M. D. (1975). The empirical development of an instrument of writing apprehension. Research in the Teaching of English, 9, 242-249.

Devine, J., Railey, K., \& Boshoff, P. (1993). The Implications of Cognitive Models in L1 and L2 Writing. Journal of Second Language Writing, 2(3), 203-225. https://doi.org/10.1016/1060-3743(93)90019-Y

Gardner, R. C., Moorcroft, R., \& MacIntyre, P.D. (1987). The role of anxiety in second language performance of language dropouts. Research bulletin no.657. London: University of Western Ontario.

Gregersen, T. S. (2003). To err is human: A reminder to teachers of language- anxious students. Foreign Language Annals, 36(1), 25-32. https://doi.org/10.1111/j.1944-9720.2003.tb01929.x

Horwitz, E. K. (2001). Language anxiety and achievement. Annual Review of Applied Linguistics, 21, 112-126.

Horwitz, E. K., Horwitz, M. B., \& Cope, J. (1986). Foreign language classroom anxiety. The Modern Language Journal, 70(2), 125-132. https://doi.org/10.2307/327317

Inal, S. (2006). The effectiveness of clustering technique on students'attitudes and on their writing achievement (Unpublished $\mathrm{PhD}$ thesis). University Dokuz Eylül.

Kamimura, T. (2000). Integration of process and product orientations in EFL writing instruction. RECL Journal $31(2), 1-28$.

Lefrançois, P. (2001). Le Point sur les Transferts dans l'Ecriture en Langue Seconde. La Revue canadienne des langues vivantes, 58(2), 223-245. https://doi.org/10.3138/cmlr.58.2.223

Leki, I. (1999). Techniques for reducing second language. In D. J. Young, (Ed.), Affect in foreign language and second language learning: A practical guide to creating a low-anxiety classroom atmosphere (pp. 64-88). New York : McGraw-Hill.

Lusignan, G. (2001). La Gestion de classe: un survol historique. Vie Pédagogique, 119, 19-22. Retrieved January 12, 2016 from, http://www.mels.gouv.qc.ca/sections/viepedagogique/numeros/119/vp119_19-22.pdf

MacIntyre, P. D., \& Gardner, R. C. (1991). Methods and results in the study of anxiety and language learning: a review of the literature. Language Learning, 41(1), 85-117. https://doi.org/10.1111/j.1467-1770.1991.tb00677.x

MacIntyre, P. D. (1995). How does anxiety affect second language learning? A reply to Sparks and Ganschow. The Modern Language Journal, 79(1), 90-99. http://www.jstor.org/stable/329395

Morissette, D. (2000). Les examens de rendements scolaires. Canada: Les Presses de l'Université de Laval.

Negari, G. M., \& Rezaabadi, O. T. (2012). Too nervous to write? The relationship between anxiety and EFL

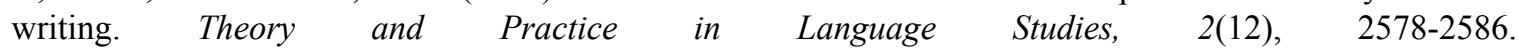
https://doi.org/10.4304/tpls.2.12.2578-2586 
Petzel, T. P., \& Wenzel, M. U. (1993). Development and initial evaluation of a measure of writing anxiety. Reports/Research bulletin no.143. Chicago: Loyola University.

Saito, Y., \& Samimy, K. K. (1996). Foreign language anxiety and language performance: A study of learner anxiety in beginning, intermediate, and advanced-level college students of Japanese. Foreign Language Annals, 29(2), 239-249. https://doi.org/10.1111/j.1944-9720.1996.tb02330.x

Simard, C. (1992). L’Ecriture et ses difficultés d'apprentissage. In R.Ouellet \& L.Savard (Eds), Pour Favoriser la Réussite Scolaire (pp.276-294). Montréal: Editions Saint-Martin.

Spolsky, B. (1989). Conditions for second language learning. Oxford: Oxford University Press.

Wang, S. (2005). Beliefs about language learning and foreign language anxiety: A study of university students learning English as a foreign language in Mainland China (Unpublished master's thesis). Victoria University.

Wanlin, P. (2007). L'analyse de contenu comme méthode d'analyse qualitative d'entretiens: une comparaison entre les traitements manuels et l'utilisation de logiciels. Recherches Qualitatives, Hors-série, 3, 243-272. Actes du colloque Bilan et prospectives de la recherche qualitative. Retrieved January 12, 2015, from http://www.recherche-qualitative.qc.ca/revue/hors_serie/hors_serie_v3/Wanlin2.pdf

Whalen, K., \& Ménard, N. (1995). L1 and L2 writers' strategic and linguistic knowledge: A model of multiple-level discourse processing. Language Learning, 45(3), 381-418. https://doi.org/10.1111/j.1467-1770.1995.tb00447.x

Young, D. J. (1986). The relationship between anxiety and foreign language oral proficiency ratings. Foreign Language Annals, 19(5), 439-445. https://doi.org/10.1111/j.1944-9720.1986.tb01032.x

Young, D. J. (1991). Creating a low-anxiety classroom environment: What does language anxiety research suggest? The Modern Language Journal, 75(4), 426-439. https://doi.org/10.2307/329492

Young, D. J. (1992). Language anxiety from the foreign language specialist's perspective: Interviews with Krashen, Omaggio Hadley, Terrell, and Rardin. Foreign Language Annals, 25(2), 157-172. https://doi.org/10.1111/j.1944-9720.1992.tb00524.x

Zamel, V. (1983). The composing process of advanced ESL students: Six case studies. TESOL Quarterly, 17(2), 165-187. https://doi.org/10.2307/3586647

\section{Appendix}

Retrospective Composing-Process Questionnaire

Read the following statements on how you have written the composition. Answer "Yes" or "No".

\begin{tabular}{|c|c|c|c|c|}
\hline Pre-Writing & Yes & No & Points \\
\hline 1.A & I thought about content before beginning to write. & & & 3 \\
\hline 1.B & $\begin{array}{c}\text { I thought about organization before beginning to } \\
\text { write. }\end{array}$ & & & 3 \\
\hline 1.C & I thought about audience before beginning to write. & & & 3 \\
\hline 2.A & I read the instructions in the task several times. & & & 1 \\
\hline 2.B & I wrote an outline. & & 1 \\
\hline 3.C & I listed ideas. & & 1 \\
\hline 3.D & I jotted down words & & 1 \\
\hline
\end{tabular}

\begin{tabular}{|c|c|c|c|c|}
\hline While-Writing & Yes & No & Points \\
\hline 3. & I thought and wrote in French from the beginning. & & & 1 \\
\hline 4. & I avoided writing whatever idea came into my mind. & & & 1 \\
\hline 5. & I tried to write as much as possible. & & & 1 \\
\hline 6. & I seldom stopped in the middle. & & & 1 \\
\hline
\end{tabular}




\begin{tabular}{|r|c|c|c|}
\hline \hline 7. & $\begin{array}{l}\text { While I wrote my composition, I paid attention to the } \\
\text { following aspects of writing: }\end{array}$ & \multicolumn{2}{|l|}{} \\
\hline A. & Content & & 3 \\
\hline B. & Audience & & 3 \\
\hline C. & Organization & & 3 \\
\hline D. & Vocabulary & & 2 \\
\hline E. & Grammar & & 2 \\
\hline F. & Spelling/punctuation & 1 \\
\hline
\end{tabular}

\begin{tabular}{|c|c|c|c|c|}
\hline Post-Writing & & Yes & No & Points \\
\hline 8. & $\begin{array}{l}\text { After I wrote my composition, I reread my } \\
\text { composition by paying attention to the following } \\
\text { aspects of writing: }\end{array}$ & & & \\
\hline A. & Content & & & 3 \\
\hline B. & Audience & & & 3 \\
\hline $\mathrm{C}$. & Organization & & & 3 \\
\hline D. & Vocabulary & & & 2 \\
\hline E. & Grammar & & & 2 \\
\hline F. & Spelling/punctuation & & & 1 \\
\hline 9. & $\begin{array}{l}\text { I revised my composition by paying attention to the } \\
\text { following aspects of writing: }\end{array}$ & & & \\
\hline A. & Content & & & 3 \\
\hline B. & Audience & & & 3 \\
\hline C. & Organization & & & 3 \\
\hline D. & Vocabulary & & & 2 \\
\hline E. & Grammar & & & 2 \\
\hline F. & Spelling/punctuation & & & 1 \\
\hline
\end{tabular}

\section{Copyrights}

Copyright for this article is retained by the author(s), with first publication rights granted to the journal.

This is an open-access article distributed under the terms and conditions of the Creative Commons Attribution license (http://creativecommons.org/licenses/by/4.0/). 